\title{
Factors influencing outcome and incidence of long-term complications in children who underwent autologous stem cell transplantation for acute myeloid leukemia in first complete remission
}

Franco Locatelli, Myriam Labopin, Juan Ortega, Giovanna Meloni, Giorgio Dini, Chiara Messina, Isaac Yaniv, Franca Fagioli, Victoria Castel, Peter J. Shaw, Augustin Ferrant, Andrea Pession, Gerard Sociè, and Francesco Frassoni, for the European Blood and Marrow Transplantation Acute Leukemia Working Party

To evaluate factors influencing outcome and incidence of long-term complications, we analyzed, in a retrospective, multicenter study, 387 children who underwent autologous hematopoietic stem cell transplantation (HSCT) for acute myeloid leukemia (AML) in first complete remission (CR). Median follow-up time from transplantation was 60 months. Transplantation of bone marrow cells was performed in 318 children, whereas in 60 patients peripheral blood progenitor cells (PBPCs) were used. In multivariate analysis, we investigated the variables influencing probability of hematopoietic recovery, transplantation-related mortality (TRM), relapse, and leukemia-free survival (LFS).
We found that use of PBPCs as stem cell sources and use of $\mathrm{BCNU}(\mathrm{N}, \mathrm{N}$-bis[2chloroethyl]- $\mathrm{N}$-nitrosourea), amsacrine, VP-16, and cytosine arabinoside (BAVC) as a preparative regimen were associated with faster neutrophil recovery. Infusion of PBPCs, young age of patients, use of BAVCs, and absence of marrow purging predicted an accelerated platelet reconstitution. The 5-year Kaplan-Meier estimates of TRM, relapse, and LFS were $3 \% \pm 1 \%$, $39 \% \pm 3 \%$ and $60 \% \pm 3 \%$, respectively. Relapse probability was increased in children given the BAVC regimen, and it was decreased after in vitro purging of hematopoietic progenitors and in children with a French-American-British classification of M3 and a time interval of 170 days or more between CR and HSCT. These 2 latter variables favorably influenced the probability of LFS, which was, by contrast, reduced with the BAVC regimen. Thirty-three percent of patients surviving more than 18 months experienced at least one late sequela; use of total body irradiation was the only predictive factor. The results obtained in this analysis can be of help in designing prospective studies of autologous HSCT in children with AML in first CR. (Blood. 2003;101:1611-1619)

두 2003 by The American Society of Hematology

\section{Introduction}

In the past 2 decades, postremission treatment, including conventional chemotherapy and allogeneic and autologous hematopoietic stem cell transplantation (HSCT), has considerably contributed to improved survival of patients with acute myeloid leukemia (AML). ${ }^{1,2}$ In particular, autologous HSCT has been largely used to prevent relapse in patients with AML who achieve complete remission (CR) after induction therapy. ${ }^{3}$ Although some randomized studies have suggested an advantage in terms of leukemia-free survival (LFS) for patients with AML in first CR who underwent autologous HSCT compared with those treated with chemotherapy alone, ${ }^{4,5}$ other reports did not confirm this observation. ${ }^{6,8-10}$ In particular, in the 4 studies focusing on pediatric patients, ${ }^{7-10}$ only one,${ }^{7}$ in which autologous transplantation was compared with no further therapy, showed an advantage in terms of LFS for patients who underwent HSCT, whereas the remaining 3 did not show any advantage in the probability of survival for patients who underwent transplantation. ${ }^{8-10}$ This reduced the enthusiasm regarding the use of autologous transplantation for childhood AML in first CR.

Other noncontrol studies on autologous HSCT in children and adolescents with AML in first CR have reported encouraging results. ${ }^{11,12}$ However, most of the control and noncontrol reports either analyzed a limited number of patients or had relatively short follow-up periods, precluding the possibility of obtaining data that allowed conclusive establishment of the impact of different factors on the outcomes for children undergoing autologous HSCT in first CR. In particular, the optimal conditioning regimen for autologous
From Oncoematologia Pediatrica, Istituto di Ricovero e Cura a Carattere Scientifico Policlinico San Matteo, Università di Pavia, Italy; European Data Management Office, Paris, France; Hospital Materno Infantil, Vall d'Hebron, Barcelona, Spain; Dipartimento di Biotecnologie Cellulari ed Ematologia, Università La Sapienza, Roma, Italy; Dipartimento di Ematologia ed Oncologia, Istituto G. Gaslini, Genova, Italy; Clinica Pediatrica, Università di Padova, Italy Bone Marrow Transplantation Unit, Schneider Children's Medical Center of Israel, Petach-Tikva, Israel; Clinica Pediatrica, Università di Torino, Italy Hospital Infantil La Fe, Valencia, Spain; Oncology Unit, Children Hospital at Westmead, Sydney, Australia; Cliniques Universitaires St Luc, Brussels, Belgium; Clinica Pediatrica, Università di Bologna, Italy; Department of Hematology, Bone Marrow Transplantation Unit, Hôpital Saint-Louis, Paris, France; Divisione di Ematologia II, Ospedale San Martino, Genova, Italy.

Submitted March 18, 2002; accepted August 7, 2002. Prepublished online as Blood First Edition Paper, October 10, 2002; DOI 10.1182/blood-200203-0764.
Supported by grants from AIRC (Associazione Italiana Ricerca sul Cancro), CNR (Consiglio Nazionale delle Ricerche), MURST (Ministero dell'Università e della Ricerca Scientifica e Tecnologica), and IRCCS (Istituto di Ricovero e Cura a Carattere Scientifico) Policlinico San Matteo (F.L.).

A complete list of the members of the European Blood and Marrow Transplantation appears in the "Appendix."

Reprints: Franco Locatelli, Oncoematologia Pediatrica, Università di Pavia, Istituto di Ricovero e Cura a Carattere Scientifico Policlinico San Matteo, P.le Golgi 2, I-27100 Pavia, Italy; e-mail: f.locatelli@smatteo.pv.it.

The publication costs of this article were defrayed in part by page charge payment. Therefore, and solely to indicate this fact, this article is hereby marked "advertisement" in accordance with 18 U.S.C. section 1734.

(C) 2003 by The American Society of Hematology 
HSCT still must be defined. The choice between regimens containing radiotherapy and regimens based on chemotherapy alone is the most important issue.

In view of the above considerations, we carried out a large, multicenter, retrospective study aimed at analyzing the impacts of disease-, patient-, and transplantation-related factors on relapse, non-leukemia-related death, and LFS of children with AML in first CR who underwent autologous HSCT. Moreover, to evaluate the sequelae experienced by long-term survivors, we evaluated the occurrence of the most common complications-namely growth impairment, thyroid complications, hypogonadism, cataract, and secondary malignancy - in our cohort of patients.

\section{Patients and methods}

The European Blood and Marrow Transplantation (EBMT) registry is a voluntary working group of transplantation centers, both pediatric and adult. Participants are required once a year to report all consecutive transplantations and follow-up. The Acute Leukemia Working Party (ALWP) of the EBMT is in charge of validating and checking submitted data to ensure data quality. This study includes patients undergoing autologous bone marrow (BM) or autologous peripheral blood progenitor cell (PBPC) transplantation who were younger than 16 years at time of transplantation, had de novo AML according to the criteria of the French-American-British (FAB) cooperative group, ${ }^{13}$ underwent transplantation between January 1980 and December 1999, and were reported to the ALWP of the EBMT group. No patient with Down syndrome was included in this study. Three hundred eighty-seven patients (204 males, 183 females) who underwent autologous HSCT at 51 centers experienced in performing transplantation of children satisfied these criteria. Data concerning patientand disease-related characteristics and transplantation outcomes were collected by standardized questionnaires of EBMT for each child enrolled in this study.

Details on patient characteristics, white blood cell (WBC) counts at diagnosis, FAB classification, number of courses needed to achieve $\mathrm{CR}$, median time interval between diagnosis and HSCT, source of stem cells, and number of cells infused are reported in Table 1. Transplantation of bone marrow progenitor cells (BMPCs) was performed in 318 children, whereas in 60 patients PBPCs were used. The remaining 9 children underwent transplantation with a combination of BMPCs and PBPCs.

Preparative regimens varied mainly according to patient age and transplantation center protocols (Table 1). One hundred fifty-seven patients underwent a radiotherapy-containing preparative regimen, whereas in the remaining 230 children chemotherapy-based myeloablative therapy was used. In the latter group, 138 children were given busulfan in combination with other cytotoxic drugs and 37 were treated with the BCNU ( N,N-bis[2chloroethyl]- $N$-nitrosourea), amsacrine, VP-16, and cytosine arabinoside (BAVC) preparative regimen. ${ }^{9,14}$

One hundred twenty patients received marrow cells purged in vitro with an active cyclophosphamide derivative (mafosfamide; Asta Z 7557). Supportive therapy and prophylaxis and treatment of infections varied among centers.

\section{Definitions}

Patients were considered in CR if they had normal neutrophil and platelet counts, less than 5\% blast cells in a BM smear, absence of circulating blasts, and absence of extramedullary leukemia cell infiltration. For the purpose of this study, patients with inv16, $\mathrm{t}(8 ; 21)$, and $\mathrm{t}(15 ; 17)$ were classified as having good prognoses (63 patients). Chromosomal abnormalities classified as poor prognostic features (32 patients) included monosomy of chromosomes 5 and 7 , anomalies of 11q, t $(6 ; 9)$, or complex karyotype (ie, more than 3 cytogenetic abnormalities). Patients with cytogenetic abnormalities other than these or with normal karyotypes were assigned to an intermediate risk group (102 patients; Table 1).
Table 1. Clinical characteristics of the 387 patients enrolled in the study

\begin{tabular}{|c|c|}
\hline Characteristic & Value \\
\hline Median age at diagnosis, y (range) & $7.3(0.1-15.6)$ \\
\hline Median age at transplantation, y (range) & $7.8(0.5-16.0)$ \\
\hline Sex, M/F & $204 / 183$ \\
\hline \multicolumn{2}{|l|}{ FAB classification } \\
\hline M0 & 6 \\
\hline M1 & 59 \\
\hline M2 & 93 \\
\hline M3 & 36 \\
\hline M4 & 71 \\
\hline M5 & 96 \\
\hline M6 & 10 \\
\hline M7 & 16 \\
\hline Median WBC count at diagnosis, $\times 10^{9} / \mathrm{L}$ (range) & $17(0.6-840)$ \\
\hline \multicolumn{2}{|l|}{ Cytogenetic abnormalities } \\
\hline Good-prognosis karyotype & 63 \\
\hline Intermediate-risk karyotype & 102 \\
\hline Poor-prognosis karyotype & 32 \\
\hline Failed/unknown & 190 \\
\hline \multicolumn{2}{|l|}{ No. induction courses to achieve first $\mathrm{CR}^{*}$} \\
\hline 1 & 234 \\
\hline 2 & 92 \\
\hline 3 or more & 29 \\
\hline Median interval diagnosis to first CR, d (range) & $38(14-354)$ \\
\hline Median interval first CR to ABMT, $d$ (range) & $114(17-830)$ \\
\hline \multicolumn{2}{|l|}{ Source of stem cells } \\
\hline BM & 318 \\
\hline PB & 60 \\
\hline $\mathrm{BM}+\mathrm{PB}$ & 9 \\
\hline \multicolumn{2}{|l|}{ Purging } \\
\hline No & 267 \\
\hline Yes & 120 \\
\hline \multicolumn{2}{|l|}{ Median no. cells infused, $\times 10^{8} / \mathrm{kg}$ (range) } \\
\hline $\mathrm{BM}, 78$ missing & $2.85(0.2-17)$ \\
\hline PB, 7 missing & $8.8(1.95-76.5)$ \\
\hline \multicolumn{2}{|l|}{ Conditioning regimen } \\
\hline TB1 + chemotherapy & 157 \\
\hline Busulfan + chemotherapy & 138 \\
\hline BAVC & 37 \\
\hline Other chemotherapy & 55 \\
\hline
\end{tabular}

*Data were missing for 32 patients.

Myeloid engraftment was defined as the first of 3 consecutive days when neutrophil levels were $0.5 \times 10^{9} / \mathrm{L}$ or higher, and platelet engraftment was defined as the first of 7 consecutive days with an unsupported platelet count of $50 \times 10^{9} / \mathrm{L}$ or higher.

In the group of 169 patients surviving in remission more than 18 months after HSCT, we investigated the occurrence of late complications through a form recording data about the development of sequelae, such as growth impairment, thyroid complications, hypogonadism, and secondary malignancy. Information was available for 147 children with a median follow-up period of 60 months (range, 18-158 months). The remaining 22 patients for whom we did not obtain data on the occurrence of late effects had follow-up intervals between 18 and 24 months. Details on the distribution of patients evaluable for the occurrence of late complications according to the time interval after HSCT are reported in Table 2.

\section{Statistical analysis}

Data were analyzed as of December 31, 2000. All analyses were performed with the SPSS computer program (SPSS, Chicago, IL). Values reported for quantitative variables were medians and ranges. The following patient or graft characteristics were analyzed for their potential prognostic value on each indicator of outcome: patient characteristics (age, sex), disease factors (WBC count at diagnosis, FAB classification, cytogenetics, number of induction courses prior to CR1, interval from diagnosis to CR1, number of 
Table 2. No. patients evaluable for occurrence of late complications subdivided according to interval from transplantation to development of sequelae

\begin{tabular}{|c|c|c|c|c|}
\hline \multirow{2}{*}{$\begin{array}{l}\text { Follow-up } \\
\text { interval, mo }\end{array}$} & \multirow{2}{*}{$\begin{array}{l}\text { No. patients } \\
\text { evaluable }\end{array}$} & \multicolumn{3}{|r|}{ Late effect } \\
\hline & & No & Yes (\%) & Specifics \\
\hline $18-24$ & 44 & 19 & $3(14)$ & 3 thyroid abnormalities \\
\hline \multirow[t]{2}{*}{$24-36$} & 22 & 18 & $4(18)$ & 3 thyroid abnormalities \\
\hline & & & & 1 growth impairment \\
\hline \multirow[t]{3}{*}{$36-48$} & 19 & 16 & $3(16)$ & 1 thyroid abnormality \\
\hline & & & & 1 chronic pulmonary insufficiency \\
\hline & & & & 1 early puberty \\
\hline \multirow[t]{5}{*}{$48-60$} & 10 & 3 & $7(70)$ & 3 growth impairment \\
\hline & & & & 1 growth impairment + hypogonadism \\
\hline & & & & 1 amenorrhea \\
\hline & & & & 1 delayed puberty \\
\hline & & & & 1 mild impairment of pulmonary function \\
\hline \multirow[t]{5}{*}{$60-72$} & 20 & 12 & $8(40)$ & 1 growth impairment \\
\hline & & & & 2 growth impairment + thyroid abnormality \\
\hline & & & & 2 thyroid abnormality \\
\hline & & & & 1 early puberty \\
\hline & & & & 2 hypogonadism \\
\hline \multirow[t]{5}{*}{$72-84$} & 10 & 3 & $7(70)$ & 2 growth impairment \\
\hline & & & & 1 growth impairment + thyroid abnormality \\
\hline & & & & 1 thyroid abnormality \\
\hline & & & & 2 hypogonadism (1 with osteopenia) \\
\hline & & & & 1 mental retardation \\
\hline \multirow[t]{3}{*}{$84-96$} & 8 & 4 & $4(50)$ & 1 growth impairment \\
\hline & & & & 2 thyroid abnormality \\
\hline & & & & 1 growth impairment + thyroid abnormality + cataract \\
\hline \multirow[t]{2}{*}{$96-108$} & 8 & 6 & $2(25)$ & 1 growth impairment \\
\hline & & & & 1 growth impairment + hypogonadism + arthritis \\
\hline \multirow[t]{3}{*}{$108-120$} & 10 & 7 & $3(30)$ & 1 growth impairment \\
\hline & & & & 1 growth impairment + thyroid abnormality + cataract \\
\hline & & & & 1 thyroid abnormality + ovarian failure \\
\hline \multirow[t]{4}{*}{ more than 120} & 18 & 10 & $8(44)$ & 3 growth impairment \\
\hline & & & & 1 thyroid abnormality \\
\hline & & & & 1 impairment of cardiac function + ovarian failure + hepatitis $C$ \\
\hline & & & & $\begin{array}{l}1 \text { growth impairment }+ \text { thyroid abnormality }+ \text { ovarian failure }+ \text { NIDDM }+ \text { hepatitis } C \\
2 \text { hypogonadism }\end{array}$ \\
\hline Total no. patients evaluable & 169 & 98 & 49 & \\
\hline
\end{tabular}

NIDDM indicates non-insulin-dependent diabetes mellitus.

consolidation courses between CR1 and transplantation, interval from CR1 to HSCT), and transplantation-related factors (source of stem cells, in vitro purging, number of nucleated cells infused per kilogram body weight, type of conditioning regimen, year of transplantation). For these prognostic analyses, continuous variables were categorized as follows: each variable was first divided into 5 categories at approximately the $20^{\text {th }}, 40^{\text {th }}, 60^{\text {th }}$, and $80^{\text {th }}$ percentiles. If the relative event rates (ratio of the observed number of events to the expected number of events in a category, assuming no variation across categories) in 2 or more adjacent categories (and the mean times-to-event) were not substantially different, these categories were grouped. If no clear pattern was observed for the primary outcome, the median was taken as cut point. ${ }^{15}$

Patients were censored at the time of relapse or of last follow-up. ${ }^{16}$ Probability of hematopoietic recovery, LFS, relapse incidence (RI), and transplantation-related mortality (TRM) were estimated by the productlimit method. ${ }^{17}$ The significance of differences between curves was estimated by the log-rank test (Mantel-Cox). All variables influencing outcome with $P<.2$ in univariate analysis were included in a multivariate analysis, with the exception of the number of cells infused because for 87 children values were lacking. Then a backward stepwise procedure was used to select covariates $(P<.10)$ to include in the final Cox proportional hazards model. ${ }^{18}$

Given that the date of appearance of late effects was not reported in the registry, we used the $\chi^{2}$ test to study prognostic factors for late complications in univariate analysis. All factors associated with $P<.2$ were then included in a stepwise logistic regression.

\section{Results}

\section{Engraftment}

Information on the kinetics of myeloid recovery was available for 379 of 387 children included in this study. Engraftment failed in 6 patients; 2 of them had received purged marrow. In the remaining 373 children, the median time to neutrophil recovery was 25 days (range, 9-138 days). In Cox analysis on the whole population, the use of PBPCs as a stem cell source $(P<.0001$; relative risk [RR], 0.33 ; $95 \%$ confidence interval $[\mathrm{CI}], 0.23-0.45)$ and the use of BAVC as a preparative regimen $(P<.0001 ; \mathrm{RR}, 0.39 ; 95 \% \mathrm{CI}$, $0.27-0.57)$ were factors predicting faster neutrophil recovery. Among patients who received transplanted marrow cells, those who underwent transplantation after 1993 had accelerated myeloid recovery (RR, 0.74), as did those given BAVC as a preparative regimen $(P=.001$; RR, $0.43 ; 95 \% \mathrm{CI}, 0.26-0.69)$. By contrast, in vitro purging with mafosfamide and number of cells infused did not have any influence on the kinetics of granulocyte recovery (data not shown).

Data on platelet recovery were reported for 361 of 387 patients analyzed. Thirty-three children did not achieve platelet reconstitution at the time of last assessment. In the remaining 328 children, 
Table 3. Univariate analysis of variables influencing LFS, RI, TRM, and OS

\begin{tabular}{|c|c|c|c|c|c|}
\hline & $\mathrm{N}$ & LFS & $\mathrm{RI}$ & TRM & os \\
\hline \multicolumn{6}{|l|}{ Median age at diagnosis, $y$} \\
\hline Younger than 7.3 & 193 & $61 \pm 4$ & $38 \pm 4$ & $2 \pm 1$ & $66 \pm 4$ \\
\hline 7.3 or older & 194 & $58 \pm 4$ & $40 \pm 4$ & $3 \pm 1$ & $64 \pm 4$ \\
\hline$P$ & & .66 & .89 & .23 & .75 \\
\hline \multicolumn{6}{|l|}{ Median age at ABMT, $y$} \\
\hline Younger than 7.8 & 193 & $61 \pm 4$ & $38 \pm 4$ & $2 \pm 1$ & $66 \pm 4$ \\
\hline 7.8 or older & 194 & $58 \pm 4$ & $40 \pm 4$ & $3 \pm 1$ & $64 \pm 4$ \\
\hline$P$ & & .81 & .92 & .57 & .92 \\
\hline \multicolumn{6}{|l|}{ Median WBC count at diagnosis } \\
\hline Lower than $17 \times 10^{9} / \mathrm{L}$ & 167 & $63 \pm 4$ & $35 \pm 4$ & $3 \pm 1$ & $65 \pm 4$ \\
\hline $17 \times 10^{9} / \mathrm{L}$ and higher & 169 & $55 \pm 4$ & $44 \pm 4$ & $1 \pm 1$ & $64 \pm 4$ \\
\hline$P$ & & .16 & .13 & .69 & .86 \\
\hline \multicolumn{6}{|l|}{ Sex } \\
\hline Male & 204 & $58 \pm 4$ & $41 \pm 4$ & $2 \pm 1$ & $63 \pm 4$ \\
\hline Female & 183 & $62 \pm 4$ & $36 \pm 4$ & $3 \pm 1$ & $67 \pm 4$ \\
\hline$P$ & & .35 & .24 & .44 & .44 \\
\hline \multicolumn{6}{|l|}{ FAB subtype } \\
\hline M3 & 36 & $77 \pm 7$ & $18 \pm 7$ & $6 \pm 4$ & $80 \pm 7$ \\
\hline $\mathrm{M} 0$ and $\mathrm{M} 6$ & 16 & $29 \pm 14$ & $71 \pm 14$ & 0 & $47 \pm 13$ \\
\hline Other subtype & 335 & $59 \pm 3$ & $40 \pm 3$ & $2 \pm 1$ & $64 \pm 3$ \\
\hline$P$ & & $.02^{*}$ & $.006^{*}$ & .5 & .13 \\
\hline \multicolumn{6}{|l|}{ Cytogenetics } \\
\hline Good & 63 & $68 \pm 6$ & $29 \pm 6$ & $5 \pm 3$ & $74 \pm 6$ \\
\hline Normal/intermediate & 102 & $61 \pm 5$ & $38 \pm 5$ & $1 \pm 1$ & $73 \pm 5$ \\
\hline Poor & 32 & $65 \pm 9$ & $33 \pm 9$ & $3 \pm 3$ & $65 \pm 9$ \\
\hline NA/failed & 190 & $56 \pm 4$ & $43 \pm 4$ & $3 \pm 1$ & $60 \pm 4$ \\
\hline$P$ & & .45 & .27 & .71 & .21 \\
\hline \multicolumn{6}{|l|}{ No. induction courses to reach CR1 } \\
\hline 1 & 234 & $63 \pm 4$ & $36 \pm 3$ & $2 \pm 1$ & $68 \pm 3$ \\
\hline 2 & 92 & $60 \pm 5$ & $39 \pm 5$ & $3 \pm 2$ & $65 \pm 5$ \\
\hline More than 2 & 29 & $48 \pm 9$ & $50 \pm 9$ & $3 \pm 3$ & $50 \pm 9$ \\
\hline$P($ trend $)$ & & .1 & .1 & .75 & $.04^{\star}$ \\
\hline 1 or 2 courses (together) & & $62 \pm 3$ & $37 \pm 3$ & $2 \pm 1$ & $67 \pm 3$ \\
\hline$P(1$ or 2 courses vs $>2)$ & & .08 & .1 & .6 & $.016^{*}$ \\
\hline \multicolumn{6}{|l|}{ Median interval diagnosis to $\mathrm{CR} 1, \mathrm{~d}$} \\
\hline Fewer than 38 & 188 & $63 \pm 4$ & $36 \pm 4$ & $2 \pm 1$ & $70 \pm 4$ \\
\hline 38 or more & 199 & $57 \pm 4$ & $41 \pm 4$ & $3 \pm 1$ & $61 \pm 4$ \\
\hline$P$ & & .1 & .17 & .24 & $.03^{*}$ \\
\hline \multicolumn{6}{|c|}{ No. consolidation courses between CR1 and ABMT } \\
\hline 3 or fewer & 145 & $63 \pm 4$ & $35 \pm 4$ & $3 \pm 2$ & $70 \pm 4$ \\
\hline More than 3 & 86 & $69 \pm 5$ & $31 \pm 5$ & 0 & $70 \pm 5$ \\
\hline$P$ & & .35 & .59 & .09 & .85 \\
\hline \multicolumn{6}{|l|}{ Interval $C R 1$ to $A B M T, d$} \\
\hline Fewer than 170 (5th percentile) & 310 & $57 \pm 3$ & $42 \pm 3$ & $3 \pm 1$ & $64 \pm 3$ \\
\hline 170 or more & 77 & $70 \pm 5$ & $29 \pm 5$ & 0 & $70 \pm 5$ \\
\hline$P$ & & $.014^{*}$ & $.04^{*}$ & .1 & .2 \\
\hline \multicolumn{6}{|l|}{ Source of stem cells } \\
\hline $\mathrm{BM}$ & 318 & $60 \pm 3$ & $38 \pm 3$ & $3 \pm 1$ & $66 \pm 3$ \\
\hline PB & 60 & $61 \pm 8$ & $37 \pm 8$ & $2 \pm 2$ & $60 \pm 10$ \\
\hline$P$ & & .81 & .74 & .76 & .64 \\
\hline \multicolumn{6}{|l|}{ Purging } \\
\hline No & 267 & $56 \pm 3$ & $43 \pm 3$ & $2 \pm 1$ & $61 \pm 3$ \\
\hline Yes & 120 & $68 \pm 5$ & $30 \pm 4$ & $3 \pm 2$ & $74 \pm 4$ \\
\hline$P$ & & .09 & $.04^{*}$ & .21 & .07 \\
\hline \multicolumn{6}{|l|}{ Conditioning regimen } \\
\hline $\mathrm{TBI}+$ other chemotherapy & 157 & $63 \pm 4$ & $34 \pm 4$ & $5 \pm 2$ & $67 \pm 4$ \\
\hline Busulfan + other chemotherapy & 138 & $59 \pm 4$ & $40 \pm 4$ & $2 \pm 1$ & $62 \pm 5$ \\
\hline BAVC & 37 & $35 \pm 8$ & $65 \pm 8$ & 0 & $49 \pm 8$ \\
\hline Other chemotherapy & 55 & $65 \pm 7$ & $34 \pm 7$ & 0 & $78 \pm 7$ \\
\hline Overall $P$ & & $.03^{*}$ & $.007^{*}$ & .08 & $.03^{*}$ \\
\hline$P$ for TBI vs no TBI & & .27 & .07 & $.012^{*}$ & .64 \\
\hline \multicolumn{6}{|c|}{$P$ for TBI + other chemotherapy vs busulfan +} \\
\hline other chemotherapy & & .43 & .18 & .12 & .51 \\
\hline
\end{tabular}


Table 3. Univariate analysis of variables influencing LFS, RI, TRM, and OS (continued)

\begin{tabular}{|c|c|c|c|c|c|}
\hline & $\mathrm{N}$ & LFS & RI & TRM & os \\
\hline \multicolumn{6}{|c|}{ Median no. nucleated cells infused BM } \\
\hline Less than $2.85 \times 10^{8} / \mathrm{kg}$ & 120 & $63 \pm 4$ & $36 \pm 5$ & $2 \pm 1$ & $71 \pm 4$ \\
\hline $2.85 \times 10^{8} / \mathrm{kg}$ or more & 120 & $54 \pm 5$ & $45 \pm 5$ & $3 \pm 1$ & $56 \pm 5$ \\
\hline$P$ & & .21 & .23 & .67 & $.03^{*}$ \\
\hline \multicolumn{6}{|l|}{ Median PB } \\
\hline Less than $8.8 \times 10^{8} / \mathrm{kg}$ & 26 & $53 \pm 11$ & $44 \pm 11$ & $5 \pm 5$ & $55 \pm 14$ \\
\hline $8.8 \times 10^{8} / \mathrm{kg}$ or more & 27 & $74 \pm 9$ & $26 \pm 9$ & 0 & $70 \pm 12$ \\
\hline$P$ & & .29 & .4 & .32 & .39 \\
\hline \multicolumn{6}{|l|}{ BM and nucleated cells } \\
\hline BM less than $2.85 \times 10^{8} / \mathrm{kg}$ & 120 & $63 \pm 5$ & $36 \pm 5$ & $2 \pm 1$ & $71 \pm 4$ \\
\hline Other & 180 & $56 \pm 4$ & $42 \pm 4$ & $3 \pm 1$ & $58 \pm 4$ \\
\hline$P$ & & .25 & .27 & .73 & $.04^{*}$ \\
\hline \multicolumn{6}{|l|}{ Year of transplantation, median } \\
\hline Before 1993 & 195 & $60 \pm 3$ & $39 \pm 3$ & $2 \pm 1$ & $65 \pm 3$ \\
\hline 1993 or later & 192 & $74 \pm 9$ & $37 \pm 4$ & $3 \pm 1$ & $66 \pm 4$ \\
\hline$P$ & & .29 & .65 & .63 & .99 \\
\hline
\end{tabular}

${ }^{\star} P \leq .05 ;$ NA indicates not applicable.

the median time to self-sustained platelet count higher than $50 \times 10^{9} / \mathrm{L}$ was 46 days (range, 11-383 days). From the Cox model, we found that the most favorable factors for platelet recovery in the overall population were infusion of PBPCs $(P=.0001 ; \mathrm{RR}, 0.53 ; 95 \% \mathrm{CI}, 0.38-0.74)$, age younger than 7.8 years $(P=.0001 ; \mathrm{RR}, 0.62 ; 95 \% \mathrm{CI}, 0.49-0.80)$, use of BAVC as a preparative regimen $(P=.0001$; RR, 0.40; 95\% CI, 0.27-0.59), and absence of marrow purging $(P=.004$; RR, $0.68 ; 95 \% \mathrm{CI}$, $0.52-0.88)$. The latter 3 variables, together with a number of cells infused more than $2.85 \times 10^{8} / \mathrm{kg}$ recipient body weight, were associated with faster platelet engraftment in the cohort of children given transplanted BMPCs (data not shown).

\section{Transplantation-related mortality}

Ten patients died of transplantation-related causes. The 5-year overall probability rate of TRM was $3 \% \pm 1 \%$. Table 3 lists the probabilities of TRM, RI, LFS, and overall survival not adjusted for differences in factors that influence transplantation outcome. In univariate analysis, only the use of total body irradiation (TBI)containing preparative regimens negatively influenced TRM; all other variables, including year of transplantation and center size, did not have any impact on the probability of death from transplantation-related complications, probably because of the limited number of events that occurred. None of the variables considered influenced TRM in multivariate analysis.

\section{Relapse}

Leukemia relapse occurred in 140 (36\%) patients. The 5-year cumulative probability of relapse was $39 \% \pm 3 \%$ for the entire group of children. Leukemia progression was the direct cause of death in 102 children, whereas 11 other children died of complications related to treatment of relapse (Table 4). In univariate

Table 4. Causes of death

\begin{tabular}{lc}
\hline \multicolumn{1}{c}{ Cause } & No. patients (\%) \\
\hline Disease progression & $102(83)$ \\
Infectious complications & $7(6)$ \\
Interstitial pneumonia & $6(5)$ \\
Cardiac toxicity & $1(0.5)$ \\
Organ failure & $2(1)$ \\
Hemorrhage & $2(1)$ \\
Other transplantation-related causes & $3(2)$ \\
\hline
\end{tabular}

analysis, FAB M3 variant, time interval of 170 days or greater (5th percentile) between CR and HSCT, and purging of hematopoietic progenitors (Figure 1) predicted lower RI (Table 3). By contrast, use of the BAVC preparative regimen was associated with an increased risk for leukemia recurrence (Figure 2). All 4 variables maintained their predictive value for RI in the Cox model (Table 5). A trend in favor of fewer relapses in TBI-containing preparative regimens was observed in univariate analysis (Table 3 ) but was not confirmed in the Cox model. We did not find any effect on RI of the time interval between remission and harvesting of hematopoietic stem cells for the overall population (data not shown).

\section{Survival and leukemia-free survival}

Overall, 264 children remain alive after HSCT; the 5-year KaplanMeier estimate of survival was $65 \% \pm 3 \%$. Among all 387 children, patients needing more than 2 cycles of induction to reach $\mathrm{CR}$, those with a time interval between diagnosis and achievement of CR of 38 days or longer (median value), and those administered BAVC had a lower probability of survival in univariate analysis (Table 3). Likewise, in the subgroup of patients who underwent transplantation with bone marrow progenitors, if the number of cells infused was greater than $2.85 \times 10^{8} / \mathrm{kg}$ (median value), it was predictive of worse outcome. From the Cox model, we found that lower probability of survival was associated with a time interval between diagnosis and achievement of CR1 at 38 days or more, whereas marrow purging was a favorable factor. A trend in favor of

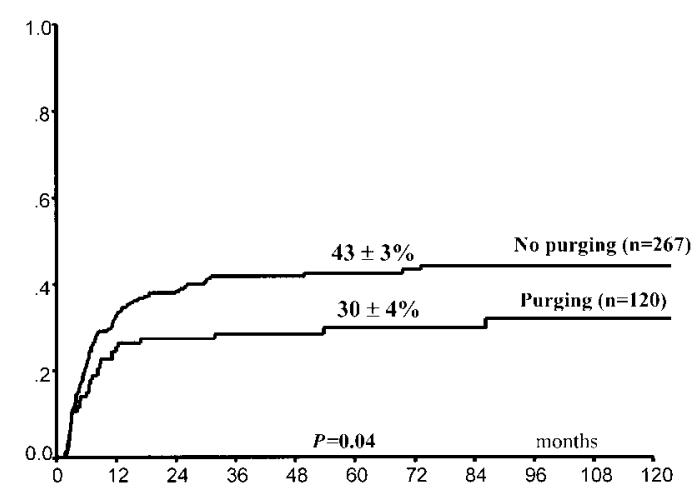

Figure 1. Posttransplantation cumulative probability of relapse according to in vitro purging of hematopoietic progenitors. 


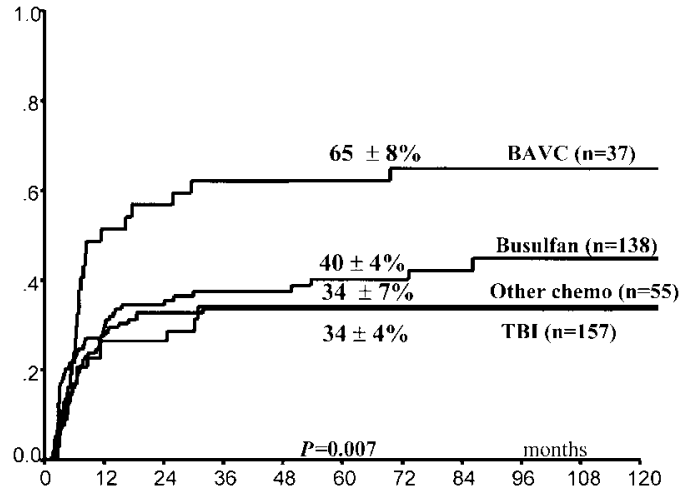

Figure 2. Posttransplantation cumulative probability of relapse according to the conditioning regimen used.

children with time intervals of 170 or more days between CR1 and HSCT was also observed (Table 5).

Two hundred thirty-seven $(61 \%)$ patients are alive in CR, with a median observation time of 60 months from transplantation (range, 1-202 months). The Kaplan-Meier estimate of LFS at 5 years was $60 \% \pm 3 \%$. Kaplan-Meier estimates of LFS for patients with the FAB M3 variant and with the M0 and M6 variants and for the remaining $\mathrm{FAB}$ subgroups were $77 \% \pm 7 \%, 29 \% \pm 14 \%$, and $59 \% \pm 3 \%$, respectively. Children with the FAB M0 and M6 variants were grouped together because of the superimposable poor outcomes. Univariate analysis of factors related to patient, leukemia, and transplantation that influenced LFS showed that the FAB M3 variant and a time interval of 170 or more days between CR1 and HSCT were associated with better outcomes, whereas the use of BAVC as a preparative regimen offered less chance of patients being alive and free from leukemia (Table 3; Figure 3). All these variables remained significant in multivariate analysis, which showed a trend for a favorable effect of purging on the probability of LFS (Table 5). Remarkably, LFS of the 32 children in the cytogenetically poor risk group was $65 \% \pm 9 \%$.

\section{Long-term side effects}

Among the 147 patients with follow-up times longer than 18 months and for whom long-term side effects was reported, 49

Table 5. Multivariate analysis of variables influencing LFS, RI, and OS

\begin{tabular}{|c|c|c|c|}
\hline & $P$ & $\mathrm{RR}$ & $95 \% \mathrm{Cl}$ \\
\hline \multicolumn{4}{|l|}{ LFS } \\
\hline \multicolumn{4}{|c|}{ Interval from $\mathrm{CR} 1$ to $\mathrm{ABMT}$, more than } \\
\hline $170 \mathrm{~d}$ & .006 & 0.52 & $0.33-0.83$ \\
\hline BAVC & .013 & 1.76 & $1.13-2.76$ \\
\hline M3 & .026 & 0.44 & $0.22-0.91$ \\
\hline Purging & .08 & 0.71 & $0.49-1.05$ \\
\hline \multicolumn{4}{|l|}{ RI } \\
\hline M3 & .012 & 0.35 & $0.15-0.79$ \\
\hline \multicolumn{4}{|c|}{ Interval from $\mathrm{CR} 1$ to $\mathrm{ABMT}, 170 \mathrm{~d}$ or } \\
\hline more & .014 & 0.56 & $0.35-0.89$ \\
\hline Purging & .036 & 0.65 & $0.43-0.97$ \\
\hline BAVC & .004 & 1.93 & $1.23-3.03$ \\
\hline \multicolumn{4}{|l|}{ os } \\
\hline \multicolumn{4}{|c|}{ Interval from diagnosis to $\mathrm{CR} 1$, more than } \\
\hline $38 d$ & .034 & 1.48 & $1.03-2.12$ \\
\hline Purging & .041 & 0.64 & $0.42-0.98$ \\
\hline \multicolumn{4}{|c|}{ Interval from $\mathrm{CR} 1$ to $\mathrm{ABMT}$, more than } \\
\hline $170 \mathrm{~d}$ & .09 & 0.66 & $0.41-1.07$ \\
\hline
\end{tabular}

With the exception of number of cells infused, all variables associated with $P<.2$ in univariate analysis were considered covariates because values were missing for 87 children.

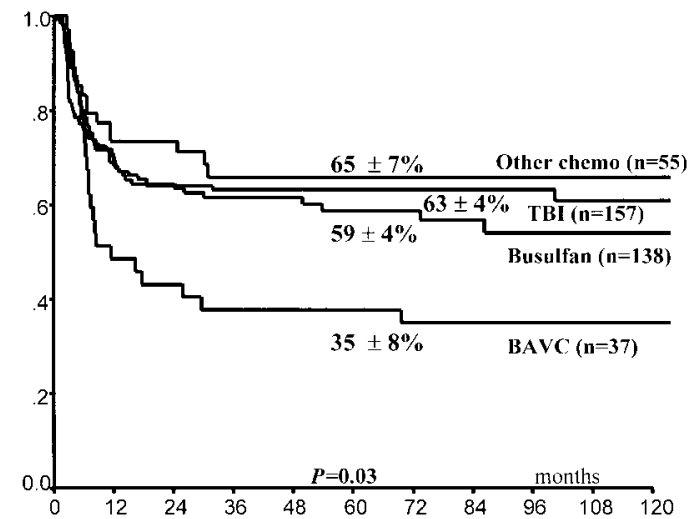

Figure 3. Kaplan-Meier estimate of LFS according to the conditioning regimen used.

(33\%) had at least one type of complication. Details on the occurrence of long-term side effects are reported in Table 2. Among the 21 patients who experienced impairment of growth velocity; 9 were given hormonal replacement therapy with recombinant human growth hormone. Abnormalities of thyroid function were observed in 20 children; 12 of them needed substitute therapy with thyroxin. Hypogonadism was reported in 13 children. One child acquired secondary myelodysplasia 4.5 years after HSCT, whereas none of the patients analyzed had a diagnosis of secondary solid tumor. In univariate and multivariate analyses, the use of TBI during the preparative regimen was the only factor statistically associated with the development of late complications as a whole (data not shown).

\section{Discussion}

This retrospective study analyzes the role played by different patient-, disease-, and transplantation-related variables in influencing outcome in a large cohort of children who underwent autograft transplantation for AML in first CR. Study results on a large number of patients, reported to an observational database and representative of the general patient population, permit detailed analyses of prognostic factors influencing outcome-often not possible to obtain from unicenter studies, which usually include a limited number of patients. The critical question regarding whether ABMT is better than chemotherapy or allograft as consolidation treatment for childhood AML in first remission has to be addressed through randomized clinical trials, some of which are already published..$^{7-10}$ This question cannot be definitively answered by a study such as ours. The value of such studies as this lies in the high number of patients analyzed and in their long follow-up, in turn enabling the identification of prognostic factors for outcome and estimation of impact of late effects.

The favorable effect of PBPC use in accelerating the recovery of hematopoiesis in children who undergo autograft transplantation has already been reported. ${ }^{19-22}$ Even though PBPCs are now preferentially used for treating children with solid tumors who have been given high-dose chemotherapy, their use in children with AML is not as frequent, mainly because of the difficulties in collecting adequate numbers of circulating hematopoietic progenitors. Moreover, none of the prospective studies on the treatment of children with AML has included a course of chemotherapy specifically designed to mobilize hematopoietic stem cells. 
Among patients given marrow cells, children who underwent transplantation more recently experienced faster neutrophil recovery. This may be explained by the use of hematopoietic growth factors, which became available only after 1990 and proved to be effective for shortening the duration of posttransplantation neutropenia. ${ }^{23-26}$ Despite their favorable effects on hematopoietic reconstitution, the infusion of PBPCs and the use of hematopoietic growth factors did not have any influence on the probability of TRM, which remained remarkably low during the study period and was not correlated with any of the variables investigated. The role of hematopoietic growth factors should be evaluated considering the benefits on morbidity, length of hospital stay, and so on. In fact, their effect on myeloid recovery could be only cosmetic. Given the cost of these cytokines, some doubts about their indiscriminate use in children given HSCT for first CR AML have been raised. 26,27

Although the TRM probability observed in our cohort confirms the results published in some recent trials on the role of autologous HSCT in childhood AML, 6,11 other studies document a probability of dying as a result of transplantation-related complications that is significantly higher than what we report. ${ }^{8}$ We do not have any obvious explanation for this discrepancy. Although we cannot exclude with absolute certainty a bias in preferentially reporting children with favorable outcomes, the $3 \%$ probability of TRM in our cohort provides evidence for the safety of autologous HSCT in these children. This value is noteworthy considering that ours was a retrospective, multicenter study that analyzed all pediatric patients with AML in first CR who underwent autograft transplantation and were reported to the EBMT registry over a long period of time.

In this study, the bone marrow of 120 patients was purged in vitro with mafosfamide at standard dosage. In vitro marrow purging did not have any effect on myeloid recovery, but it delayed the kinetics of platelet engraftment. Because it has been demonstrated that leukemia cells harvested with the autologous graft may at least contribute to posttransplantation relapse, ${ }^{28}$ there is a theoretical, strong rationale for supporting the choice of marrow purging before HSCT. Using the Cox model, we documented that purging was associated with a lower probability for leukemia recurrence and increased overall survival and with a trend toward a better LFS. Our results confirm the findings reported by Gorin et $\mathrm{al}^{29}$ and more recently by Miller et al.$^{30}$ In both these studies, which analyzed autologous HSCT for AML in adults and children, a lower risk for leukemia recurrence was observed in patients given purged grafts. ${ }^{29,30}$ Thus, our results indicate that purging of hematopoietic progenitors should be used before autograft transplantation in childhood AML.

Children with acute promyelocytic leukemia had the lowest probability for relapse and the best chance for LFS. Excellent results on these patients have been reported using a combination of chemotherapy and all-trans retinoic acid. ${ }^{31-33}$ Neither autologous nor allograft HSCT is considered any longer to be electively indicated in patients with this type of leukemia in molecular remission during or at time of treatment discontinuation. This is confirmed in our cohort; only 11 of 36 children with AML M3 FAB subtype reported in this study underwent transplantation after 1993.

Even though the number of patients analyzed is limited, our results indicate that children with AML M0 and M6 have the lowest chance for cure by autograft transplantation. In view of the improved results recently reported in patients who received transplants from matched donors on the basis of high-resolution techniques of molecular typing for HLA class 1 and class 2 antigens, ${ }^{34,35}$ these children could be considered for allografts from unrelated donors. We did not find a worse outcome for patients with megakaryoblastic leukemia, an AML variant recently reported to be associated with a dismal prognosis, especially when an allograft was not used to consolidate a state of remission. ${ }^{36}$

In our cohort, the overall probability of LFS was $60 \% \pm 3 \%$, a value at least comparable with those reported in other prospective or retrospective studies, most of which enrolled fewer patients and had shorter observation times. ${ }^{7-12}$ Of particular interest are the data on patients with poor-risk cytogenetic characteristics, in whom the results obtained with chemotherapy are usually less satisfactory than those obtained in children with inv 16 or $\mathrm{t}(8 ; 21) .{ }^{6}$ The 2 major biases of retrospective studies on patients who undergo transplantation are the so-called time-censoring effect (ie, patients who undergo transplantation late after the achievement of CR may be at low risk for relapse given that with increasing length of remission, the risk for recurrence decreases) and the possibility that patients selected for autologous HSCT have a different intrinsic prognosis than those who are not. We found that children who underwent transplantation 170 or more days after CR1 (which corresponds to the fifth percentile of the interval from CR1 to autograft) had a $70 \% \pm 5 \%$ probability for LFS, whereas the value for patients with shorter time intervals between CR and HSCT was $57 \% \pm 3 \%$. This difference was statistically significant in multivariate analysis. A long time interval between CR1 and HSCT also predicted a lower risk for relapse from the Cox model. It remains questionable whether these findings reflect a selection bias in that children who undergo transplantation later have a lower risk for relapse, a beneficial effect deriving from additional consolidation courses useful to reduce the tumor load in the patient (in vivo purging), or a combination of these 2 factors. To avoid the risk for early and late toxicity from autologous transplantation in patients with a high chance for cure from chemotherapy, it can be suggested that HSCT, if included in the treatment of a child with AML, be performed within the first 6 months after CR. Changes in the overall treatment strategy of AML, such as the introduction of high-dose Ara-C during consolidation, might have had an impact on the results. This, however, cannot be revealed by a retrospective registry study covering a 20-year period.

Our results on the BAVC regimen confirm the data of a previously published randomized Italian study that documented a comparable, albeit poor, chance for LFS in children with AML in first CR who were treated with consolidation chemotherapy or with autologous HSCT after the BAVC preparative regimen. ${ }^{9}$ In our cohort this preparative regimen was mainly used in the era before the introduction of high-dose Ara-C during consolidation therapy and in patients whose marrow cells were not purged in vitro. It is reasonable to hypothesize that both factors contributed to the inferior results of the BAVC regimen.

We did not find any advantage in terms of LFS for children given a TBI-containing preparative regimen, which, in some previous reports, ${ }^{11,37,38}$ seemed able to improve the outcome of autologous HSCT. By contrast, radiotherapy was the only factor associated in multivariate analysis with the occurrence of late effects in our cohort. One third of our patients surviving more than 18 months after HSCT developed at least one side effect, and this percentage increased with increasing time from transplantation (Table 2). Because of the retrospective, multicenter nature of the study, the reported percentages should be taken to represent the absolute minimum seen in patients with these disease characteristics. Growth retardation, hypothyroidism, and hypogonadism were the most frequent complications; in several patients they necessitated hormone replacement therapy. Other studies have demonstrated that TBI is the most important factor predisposing to the 
development of late sequelae $\mathrm{e}^{39-42}$ that may have a particularly deleterious impact on the quality of life of surviving pediatric patients. Thus, in view of our results showing the lack of benefit of TBI as part of the preparative regimen and the high incidence of radiation-induced sequelae, it is suggested that radiotherapy no longer be included in future trials evaluating the role of autologous HSCT in childhood AML. Promising results from the use of high-dose melphalan as a preparative regimen have been recently reported. ${ }^{12,43,44}$

Young age, male sex, use of TBI during the preparative regimen, chronic graft-versus-host disease, and an intrinsic genetic predisposition to cancer (eg, Fanconi anemia) have been reported as risk factors for the development of secondary malignancies in patients who undergo HSCT. ${ }^{45-48}$ In our cohort, only one child had a secondary malignancy-myelodysplastic syndrome. Although the median follow-up of this study is insufficient to completely exclude the possible development of secondary cancers in the future, this observation suggests that children who undergo autologous HSCT are not particularly prone to this kind of complication. This finding also represents a reassuring message for using some form of conditioning therapy when performing autograft transplantation combined with gene therapy. In summary, our large retrospective study provides information on factors that influence the outcome and the incidence of long-term complications in children with AML in first CR who undergo autologous HSCT, and it can be of help in designing further prospective studies on the role of this therapy.

\section{Acknowledgment}

We thank Emmanuelle Polge for her valuable help in collecting the data.

\section{References}

1. Lowenberg B, Downing JR, Burnett A. Acute myeloid leukemia. N Engl J Med. 1999;341:10511062.

2. Vormoor J, Boos J, Stahnke K, et al. Therapy of childhood acute myelogenous leukemia. Ann Hematol. 1996;73:11-24.

3. Gorin NC. Autologous stem cell transplantation in acute myelocytic leukemia. Blood. 1998;92:1073 1090

4. Zittoun RA, Mandelli F, Willemze R, et al. Autologous or allogeneic bone marrow transplantation compared to intensive chemotherapy in acute myelogenous leukemia. N Engl J Med. 1995;332 217-223.

5. Burnett AK, Goldstone AH, Stevens RMF, et al. Randomized comparison of addition autologous bone marrow transplantation to intensive chemotherapy for acute myeloid leukemia in first remission: results of MRC AML 10 Trial. Lancet. 1998; 351:700-708.

6. Cassileth PA, Harrigton DP, Appelbaum FR, et al. Chemotherapy compared with autologous or allogeneic bone marrow transplantation in the management of acute myeloid leukemia in first remission. N Engl J Med. 1998;339:1649-1656.

7. Stevens RF, Hann IM, Wheatley K, Gray RG Marked improvements in outcome with chemotherapy alone in paediatric acute myeloid leukemia: results of the United Kingdom Medical Research Council's $10^{\text {th }} \mathrm{AML}$ trial. Br J Haematol. 1998;101:30-40.

8. Ravindranath $\mathrm{Y}$, Yeager AM, Chang MN, et al. Autologous bone marrow transplantation versus intensive consolidation chemotherapy for acute myeloid leukemia in childhood. $\mathrm{N}$ Engl $\mathrm{J}$ Med. 1996;334:1428-1434.

9. Amadori S, Testi AM, Aricò M, et al. Prospective comparative study of bone marrow transplantation and postremission chemotherapy for childhood acute myelogenous leukemia. J Clin Oncol. 1993:11:1046-1054.

10. Woods WG, Neudorf S, Gold S, et al. A comparison of allogeneic bone marrow transplantation, autologous bone marrow transplantation, and aggressive chemotherapy in children with acute myeloid leukemia in remission: a report from Children's Cancer Group. Blood. 2001;97:56-62.

11. Bonetti F, Zecca M, Pession A, et al. Total-body irradiation and melphalan is a safe and effective conditioning regimen for autologous bone marrow transplantation in children with acute myeloid leukemia in first remission. J Clin Oncol. 1999;17: 3729-3735.

12. Tiedemann K, Waters KD, Tauro GP, et al. Results of intensive therapy in childhood acute myeloid leukemia, incorporating high-dose melpha- lan and autologous bone marrow transplantation in first complete remission. Blood. 1993:82.37303738

13. Bennett JM, Catovsky D, Daniel MT, et al. Proposed revised criteria for the classification of acute myeloid leukemia: a report of the FrenchAmerican-British cooperative group. Ann Intern Med. 1985;103:620-625.

14. Meloni G, De-Fabritiis P, Petti MC, Mandelli F. $\mathrm{BAVC}$ regimen and autologous bone marrow transplantation in patients with acute myelogenous leukemia in second remission. Blood. 1990;75:2282-2285.

15. Byar DP. Identification of prognostic factors. In Buyse ME, Staquet MJ, Sylvester RJ, eds. Cancer clinical trials: methods and practice. Oxford, United Kingdom: Oxford Medical Publications; 1988;423-443.

16. Clift R, Goldman JM, Gratwohl A, Horowitz M. Proposal for standardized reporting of bone marrow transplantation for leukemia. Bone Marrow Transplant. 1989;4:445-448.

17. Kaplan EL, Meier P. Nonparametric estimation from incomplete observations. J Am Stat Assoc. 1958;53:457-481.

18. Cox DR. Regression models and life tables. J R Stat Soc. 1972;34:187-202.

19. Madero L, Gonzalez-Vicent M, Ramirez M, Diaz MA. G-CSF-mobilized PBSCT in children with AML in first complete remission. Bone Marrow Transplant. 1999;23:975-976.

20. Hartmann O, Le-Corroller AG, Blaise D, et al. Pe ripheral blood stem cell and bone marrow transplantation for solid tumors and lymphomas: hematologic recovery and costs - a randomized, controlled trial. Ann Intern Med. 1997;126:600 607.

21. Le Corroller AG, Faucher C, Auperin A, et al. Autologous peripheral blood progenitor-cell transplantation versus autologous bone marrow transplantation for adults and children with nonleukaemic malignant disease: a randomized economic study. Pharmacoeconomics. 1997;11: 454-463.

22. Locatelli F, Pedrazzoli P. Recombinant human G-CSF: how wide is the field of clinical applicability? Haematologica. 1995;80:199-205.

23. Madero L, Muonz A, Diaz de Heredia A et al. GCSF after autologous bone marrow transplantation for malignant diseases in children: Spanish Working Party for Bone Marrow Transplantation in Children. Bone Marrow Transplant. 1995:15: 349-351.

24. Saarinen UM, Hovi L, Juvonen $E$, Riikonen $P$, Mottonen M, Makipernaa A. Granulocyte-colony stimulating factor after allogeneic and autologous bone marrow transplantation in children. Med Pediatr Oncol. 1996;26:380-386.

25. Suzue T, Takaue Y, Watanabe A, et al. Effects of rhG-CSF (filgrastim) on the recovery of hematopoiesis after high-dose chemotherapy and autologous peripheral blood stem cell transplantation in children: a report from the Children's Cancer and Leukemia Study Group of Japan. Exp Hematol. 1994;22:1197-1202.

26. Kawano Y, Takaue Y, Mimaya J, et al. Marginal benefit/disadvantage of granulocyte colonystimulating factor therapy after autologous blood stem cell transplantation in children: results of a prospective randomized trial. The Japanese Cooperative Study Group of PBSCT. Blood. 1998; 92:4040-4046.

27. Schaison G, Eden OB, Henze G, et al. Recommendations on the use of colony-stimulating factors in children: conclusions of a European panel. Eur J Pediatr. 1998;157:955-966.

28. Brenner MK, Rill DR, Moen RC, et al. Genemarking to trace origin of relapse after autologous bone-marrow transplantation. Lancet. 1993;341: 85-89.

29. Gorin NC, Labopin M, Meloni G, et al. Autologous bone marrow transplantation for acute myeloblastic leukemia in Europe: further evidence of the role of marrow purging by mafosfamide. Leukemia. 1991;5:896-904.

30. Miller CB, Rowlings PA, Zhang MJ, et al. The effect of graft purging with 4-hydroperoxycyclophosphamide in autologous bone marrow transplantation for acute myelogenous leukemia. Exp Hematol. 2001;29:1336-1346.

31. Mandelli F, Diverio D, Avvisati G, et al. Molecula remission in PML/RAR $\alpha$-positive acute promyelocytic leukemia by combined all-trans retinoic acid and idarubicin (AIDA) therapy: Gruppo Italiano Malattie Ematologiche Maligne dell'Adulto and Associazione Italiana di Ematologia ed Oncologia Pediatrica Cooperative Groups. Blood. 1997;90:1014-1021

32. Testi AM, Moleti ML, Del Giudice I, et al. Acute promyelocytic leukemia (APL) in children: results of the "AIDA" Italian protocol [abstract]. Blood. 2000;96(suppl 1):467.

33. Tallman MS, Andersen JW, Schiffer CA, et al. Alltrans retinoic acid in acute promyelocytic leukemia. N Engl J Med. 1997;337:1021-1028.

34. Petersdorf EW, Gooley TA, Anasetti C, et al. Optimizing outcome after unrelated marrow transplantation by comprehensive matching of HLA class I and II alleles in the donor and recipient. Blood. 1998:92: 3515-3520.

35. Sasazuki T, Juji T, Morishima Y, et al. Effect of 
matching of class I HLA alleles on clinical outcome after transplantation of hematopoietic stem cells from an unrelated donor. N Engl J Med. 1998;339:1177-1193.

36. Athale UH, Razzouk I, Raimondi SC, et al. Biology and outcome of childhood acute megakaryoblastic leukemia: a single institution's experience. Blood. 2001;97:3727-3732.

37. Vignetti M, Rondelli R, Locatelli F, et al. Autologous bone marrow transplantation in children with acute myeloblastic leukemia: report from the Italian National Pediatric Registry (AIEOP-BMT). Bone Marrow Transplant. 1996;18(suppl 2):59 62.

38. Ortega JJ, Olivé T, Diaz de Heredia C, et al. Allogeneic and autologous bone marrow transplantation in AML in first remission: the Spanish experience. Bone Marrow Transplant. 1996;18(suppl 2):53-58.

39. Giorgiani G, Bozzola M, Locatelli F, et al. Role of busulfan and total body irradiation on growth of pre-pubertal children receiving bone marrow transplantation and results of treatment with recombinant human growth hormone. Blood. 1995; $86: 825-831$
40. Leahey AM, Teunissen H, Friedman DL, et al. Late effects of chemotherapy compared to bone marrow transplantation in the treatment of pediatric acute myeloid leukemia and myelodysplasia. Med Pediatr Oncol. 1999;32:163-169.

41. Giorgiani G, Sommaruga MG, Zecca M, et al. Thyroid complications in children given bone marrow transplantation (BMT) [abstract]. Bone Marrow Transplant. 2000;25(suppl 1):S52.

42. Michel G, Gluckman E, Esperou-Bourdeau H, et al. Allogeneic bone marrow transplantation for children with acute myeloblastic leukemia in first complete remission: impact of conditioning regimen without total body irradiation-a report from the Societe Francaise de Greffe de Moelle. J Clin Oncol. 1994;12:1217-1222.

43. Yaniv I, Ash S, Stark B, et al. Childhood acute myeloid leukemia: consolidation with high dose melphalan and autologous stem cell transplantation-a single centre experience [abstract]. Bone Marrow Transplant. 1997;19(suppl 1):101.

44. Cesaro S, Meloni G, Messina C, et al. Highdose melphalan in autologous hematopoietic stem cell transplantation for acute myeloid leukemia: results of a retrospective analysis of the
Italian pediatric group for bone marrow transplantation. Bone Marrow Transplant. 2001;28: 131-136.

45. Michel G, Socié G, Gebhard F, et al. Late effects of allogeneic bone marrow transplantation for children with acute myeloblastic leukemia in first complete remission: the impact of conditioning regimen without total body irradiation-a report from the Societe Francaise de Greffe de Moelle. J Clin Oncol. 1997;15:2238-2246.

46. Socie G, Curtis RE, Deeg HJ, et al. New malignant diseases after allogeneic marrow transplantation for childhood acute leukemia. J Clin Oncol. 2000;18:348-357.

47. Socie G, Henry-Amar M, Bacigalupo A, et al. Malignant tumors occurring after treatment of aplastic anemia: European Bone Marrow Transplantation-Severe Aplastic Anemia Working Party. N Engl J Med. 1993;329:1152-1157.

48. Curtis Re, Rowlings PA, Deeg HJ, et al. Solid cancers after bone marrow transplantation. N Engl J Med. 1997;336:897-904.

\section{Appendix}

\section{Members of the European Blood and Marrow Transplantation Acute Leukemia Working Party}

Prof P. Ljungman, Huddinge University Hospital, Huddinge, Sweden; Prof N.C. Gorin , Hôpital Saint Antoine, Paris, France; Prof H.G. Prentice, Royal Free Hospital and School of Medicine, London, United Kingdom; Dr U. Pihkala, Children's Hospital, Helsinki, Finland; Dr B. Rio, Hôtel Dieu, Paris, France; Prof A.H. Goldstone, University College London Hospital, United Kingdom; Prof D. Blaise, Institut Paoli Calmettes, Marseille, France; Prof F. Mandelli, Ematologia, Univ. "La Sapienza", Rome, Italy; Prof J.Y. Cahn, Hôpital Jean Minjoz, Besançon, France; Dr A. Ferrant, Cliniques Universitaires St. Luc, Brussels, Belgium; Dr A. Schattenberg, University Medical Center St. Radboud, Nijmegen, The Netherlands; Prof A. Torres Gomez, Córdoba Hospital, Córdoba, Spain; Dr A. Iriondo, Hospedale Universitario 'Marqués de Valdecilla', Santander, Spain; Dr P. Di Bartolomeo, Ospedale Civile, Pescara, Italy; Dr J.L. Harousseau, Hôtel Dieu, Nantes, France; Prof J. Sierra , Hospital Santa Creu i Sant Pau, Barcelona, Spain; Dr B. Simonsson, University Hospital, Uppsala, Sweden; Prof P. Colombat, Hopital Bretonneau, Tours, France; Dr G. Dini, Institute G. Gaslini, Genova, Italy; Dr. Uderzo C, Ospedale San Gerardo, Monza, Italy; Prof. García-Conde J, Hospital Clínico Universitario, Valencia, Spain; Dr S. Lenhoff, University Hospital, Lund, Sweden; Dr C. Messina, Clinica di Oncoematologia Pediatrica, Padova, Italy; Dr E.P. Alessandrino, Policlinico San Matteo, Pavia, Italy; Dr I. Majolino, Ospedale S. CamilloForlanini, Rome, Italy; Dr A. Fasth, Queen Silvia Children's Hospital, Goeteburg, Sweden; Dr B. Hertenstein, Medical School of Hannover, Hannover, Germany; Dr C. Coze, Hopital d'Enfants de la Timone, Marseille, France; Dr B. Labar, University Hospital Centre-Rebro, Zagreb, Croatia; Dr F. Fagioli, Ospedale Regina Margherita, Torino, Italy; Prof G. De Rossi, Ospedale Bambino Gesù, Rome, Italy; Prof D. Bobev, Children's Onco-Hematology Clinic, Sofia, Bulgaria; Prof P. Ernst, King Faisal Hospital, Riyadh, Saudi Arabia; Dr O. Hartmann, Institut Gustave Roussy, Villejuif, France; Dr A.M. Will, Royal Manchester Children's Hospital,
Pendlebury, United Kingdom; Prof A.M. Carella, IRCCS, Casa Sollievo della Sofferenza, San Giovanni Rotondo, Italy; Dr G. Visani, Pesaro Hospital, Pesaro, Italy; Dr F. Locatelli, IRCCS Policlinico San Matteo, Pavia, Italy; Dr A. Fassas, The George Papanicolaou General, Exokhi (Thessaloniki), Greece; Dr P. Iacopino, Azienda Ospedaliera, Reggio Calabria, Italy; Prof F. Demeocq, Hôtel Dieu, Toulouse, France; Dr G. Gurman, Ankara University, Ibni Sina Hospital, Ankara, Turkey; Dr M. Attal, Hôpital de Purpan, Toulouse, France; Dr E. Vilmer, Hôpital Robert-Debré, Paris, France; Dr D. Carrera Fernández, Hospital Covadonga, Oviedo, Spain; Dr V. Castel, Hospital Infantil La Fe, Valencia, Spain; Dr M.A. Sanz, Hospital Universitario La Fe, Valencia, Spain; Dr J.H. Bourhis, Institut Gustave Roussy, Villejuif, France; Prof G. Leverger, Hôpital d'Enfants Armand-Trousseau, Paris, France; Prof P. Bordigoni, CHU de Nancy Hôpitaux de Brabois-Hôpital d'Enfants, Nancy, France; Dr B.E. Gibson, Royal Hospital for Sick Children, Glasgow, United Kingdom; Dr R.P. Herrmann, Royal Perth Hospital, Perth, Australia; Dr P.J. Shaw, The Children's Hospital at Westmead, Sydney, Australia; Prof K.M. Abdulkadirov, Russian Institute of Hematology and Transfusiology, Saint Petersburg, Russia; Dr A.M. Martínez-Rubio, Hospital Infantil La Paz, Madrid, Spain; Prof H. Everaus, Tartu University Clinics, Tartu, Estonia; Dr A. Baruchel, Hôpital St. Louis, Paris, France; Prof F. Zintl, University of Jena, Germany; Dr I. Yaniv, Schneider Children's Medical Center of Israel, Petach-Tikva, Israel; Prof A. Granena, Clínica Corachan, Barcelona, Spain; Prof P. Jacobs, Constantiaberg Medi-Clinic, Cape Town, South Africa; Dr E. Volpe, Ematologia 'Giovanni di Guglielmo', Avellino, Italy; Dr A. Pession, University of Bologna, Bologna, Italy; Dr G. Broccia, Ospedale Oncologico, Cagliari, Italy; Prof P. Macchia, University of Pisa, Italy; Dr G. Souillet, Hôpital Debrousse, Lyon, France; Dr J.F. Rossi, University Hospital, Montpellier, France; Prof P. Tron, CHU de Rouen Hôpital Charles Nicolle, Rouen, France; and Dr B. Pignon, Hôpital Robert Debré, Reims, France. 